\title{
Non-quantal Release of Acetylcholine at a Developing Neuromuscular Synapse in Culture ${ }^{1}$
}

\author{
YI-AN SUN AND MU-MING POO \\ Department of Physiology and Biophysics, University of California, Irvine, California 92717
}

\begin{abstract}
Local, pulsed application of d-tubocurarine at neuromuscular synapses in embryonic Xenopus nerve-muscle culture resulted in a transient hyperpolarization of muscle membrane potential. Miniature endplate potentials (MEPPs) were abolished during the hyperpolarization and recovered after the return of resting membrane potential. The magnitude of hyperpolarization was independent of the frequency of MEPPs before curarization, and it had an average peak value of 4.3 $\mathrm{mV}$ in medium containing physiological levels of $\mathrm{Ca}^{2+}$. Prolonged application of curare or $\alpha$-bungarotoxin led to sustained hyperpolarizations up to $8 \mathrm{mV}$ in magnitude. Denervation produced by mechanically removing the neurite from the muscle cell also produced similar hyperpolarization, and curarization after denervation was without significant hyperpolarizing effect. Increasing the extracellular $\mathrm{Ca}^{2+}$ concentration to about $8 \mathrm{~mm}$ abolished the curare-induced hyperpolarization response, in sharp contrast to its effect in elevating the frequency of MEPPs. Taken together, our results indicate that innervated embryonic muscle cells were maintained at a depolarized state relative to that of uninnervated muscle cells by a steady, spontaneous release of acetylcholine (ACh) from the innervating neurite. The cellular mechanism underlying this mode of ACh release appears to be different from that of the quantal $\mathrm{ACh}$ release responsible for MEPPs.
\end{abstract}

The nerve impulse is transmitted across the neuromuscular junction through the triggering of a simultaneous release from the nerve terminal of many packages, or "quanta," of acetylcholine (ACh) molecules, which open the ionic channels in the postsynaptic muscle membrane and induce depolarization and excitation of the muscle cell (del Castillo and Katz, 1954). In the absence of a nerve impulse, quantal release of $\mathrm{ACh}$ occurs randomly at a low frequency, as indicated by the appearance of small muscle membrane depolarizations, or miniature endplate potentials (MEPPs), that can be detected at the muscle cell near the synaptic junction (Fatt and Katz, 1952). Previous biochemical and physiological evidence suggests that a substantial amount of $A C h$ is also released from the nerve by a mechanism independent of nerve impulse activity or the MEPPs

Received April 6, 1984; Revised July 23, 1984;

Accepted August 22, 1984

\footnotetext{
1 This work was supported by National Institutes of Health Grant NS-17558 and National Science Foundation Grant 83-09336. We thank S. Young and $\mathrm{M}$. McCloskey for comments on the manuscript. $Y$-a. $S$. is on leave from Shanghai Institute of Physiology, Shanghai, China.

${ }^{2}$ To whom correspondence should be addressed at his present address: Section of Molecular Neurobiology, Yale School of Medicine, New Haven, CT 06510.
}

(Mitchell and Silver, 1963; Fletcher and Forrcster, 1975; for review see Tauc, 1982). This "non-quantal" release of ACh molecules at mature neuromuscular junctions was first detected electrophysiologically by Katz and Miledi (1977). They observed a hyperpolarization of the muscle membrane of about $40 \mu \mathrm{V}$ upon local application of curare near the frog endplates which were treated with cholinesterase inhibitors. This finding suggests that at the resting state there is a constant leakage of $\mathrm{ACh}$ from the nerve terminal, resulting in a steady depolarization of postsynaptic muscle membrane. A similar hyperpolarizing effect of curare has also been observed in mouse diaphragm muscle endplates (Vyskocil and Illes, 1977).

In the present study, we characterized for the first time the nonquantal release of $\mathrm{ACh}$ at a developing neuromuscular synapse. We found that a hyperpolarization of several millivolts can be induced by local application of curare at nerve-muscle junctions in Xenopus embyronic cell cultures without anticholinesterase treatment. This hyperpolarization appears to be independent of the quantal release associated with the MEPPs. It is associated with the presence of the neurite on the muscle cell and can be selectively abolished by raising extracellular $\mathrm{Ca}^{2+}$ concentration. This work has been reported previously in a brief form (Sun and Poo, 1983).

\section{Materials and Methods}

Preparation of the culture. Xenopus nerve-muscle cultures were prepared by previously reported procedures (Spitzer and Lamborghini, 1976; Anderson et al., 1977). Briefly, the neural tube and the underlying mesodermal tissue were dissected out from a 1-day-old Xenopus embryo (stages 19 to 23; Nieuwkoop and Faber, 1967) and incubated in dissociation solution free of $\mathrm{Ca}^{2+}$ and $\mathrm{Mg}^{2+}(58.2 \mathrm{~mm} \mathrm{NaCl}, 0.7 \mathrm{~mm} \mathrm{KCl}, 0.3 \mathrm{~mm}$ EDTA, 250 international units of penicillin-streptomycin; $\mathrm{pH} 7.8)$. Collagenase $(1 \mathrm{mg} / \mathrm{ml}$, Sigma type III) was added to the dissociation solution for 10 to $15 \mathrm{~min}$ when embryos of stages 21 to 23 were used. The dissociated cells, consisting of neural tube neurons and myotomal muscles, were plated on pieces of coverglass that were attached to the bottom of plastic dishes (Falcon). The culture medium contained $60 \%$ Leibovitz medium (GIBCO), $5 \%$ fetal bovine serum (GIBCO), and $35 \%$ distilled water. The $\mathrm{pH}$ of the culture medium was 7.4 . Within $4 \mathrm{hr}$ of culture, neurite outgrowth from many of the dissociated neurons was observed, and functional synapses between the neurite and dissociated myotomal muscle cells were detected soon after the establishment of contact between the neurites and muscle cells (see also Kidokoro and Yeh, 1982). Cultures that were from $8 \mathrm{hr}$ to 3 days old were used in the present study.

Electrophysiology. Conventional methods of intracellular recording were used. The muscle cells were impaled with glass microelectrodes (resistance, 80 to 150 megohms), and the muscle membrane potential was monitored continuously with a microelectrode amplifier (Getting M5) connected to a storage oscilloscope (Tectronix) and a fast-transient recorder (Gould 2200). The normal recording solution consisted of $67 \mathrm{~mm} \mathrm{NaCl}, 1.6 \mathrm{mM} \mathrm{KCl}, 1.6$ $\mathrm{mM} \mathrm{CaCl} \cdot 2 \mathrm{H}_{2} \mathrm{O}, 2 \mathrm{~mm}$ glucose, and $8 \mathrm{~mm}$ HEPES (Kidokoro and Yeh, 1982). Prolonged, stable recording was obtained for periods up to $1 \mathrm{hr}$.

Drug application. Local pressure ejection of $d$-tubocurarine (curare) was done using a glass micropipette (tip opening, 5 to $10 \mu \mathrm{m}$ ) filled with curarecontaining culture medium. The pressure was controlled with a microliter syringe. The curare pipette was kept outside the culture bath before the onset of the experiment, quickly lowered to proper position when local curarization was desired, and removed from the bath immediately after use. The culture medium was substituted with fresh medium at regular intervals to wash out the ejected curare as well as any free ACh. The latter was presumably due to the spontaneous ACh release from the neurons and/or 
other cell types in the culture. Local application of $\alpha$-bungarotoxin was done in the same manner as that for curare.

Denervation. Denervation of the neurite-contacted muscle cell was performed mechanically by using a micropipette to pull the neurite slowly away from the muscle, with the intracellular electrode remaining in the muscle cell. Muscle cells that showed MEPPs but were contacted by only a single neurite were selected for the denervation experiment. Best results were obtained in muscle cells which did not make extensive contact with the neurite.

\section{RESULTS}

Spontaneous quantal release of ACh. Intracellular recording from a neurite-contacted muscle cell in 1- to 2-day-old Xenopus nervemuscle cultures frequently but not always showed spontaneous MEPPs. The appearance of MEPPs and, occasionally, large action potential-like depolarizations accompanied by the twitching of the muscle cell indicated that functional synapses were established at the neurite-muscle contacts. Figure 1 depicts a typical nerve-muscle preparation and the appearance of MEPPs recorded intracellularly from a nerve-contacted muscle cell. The larger depolarizations are not endplate potentials evoked by nerve impulses, since they persist in the presence of tetrodotoxin, which blocks action potentials in
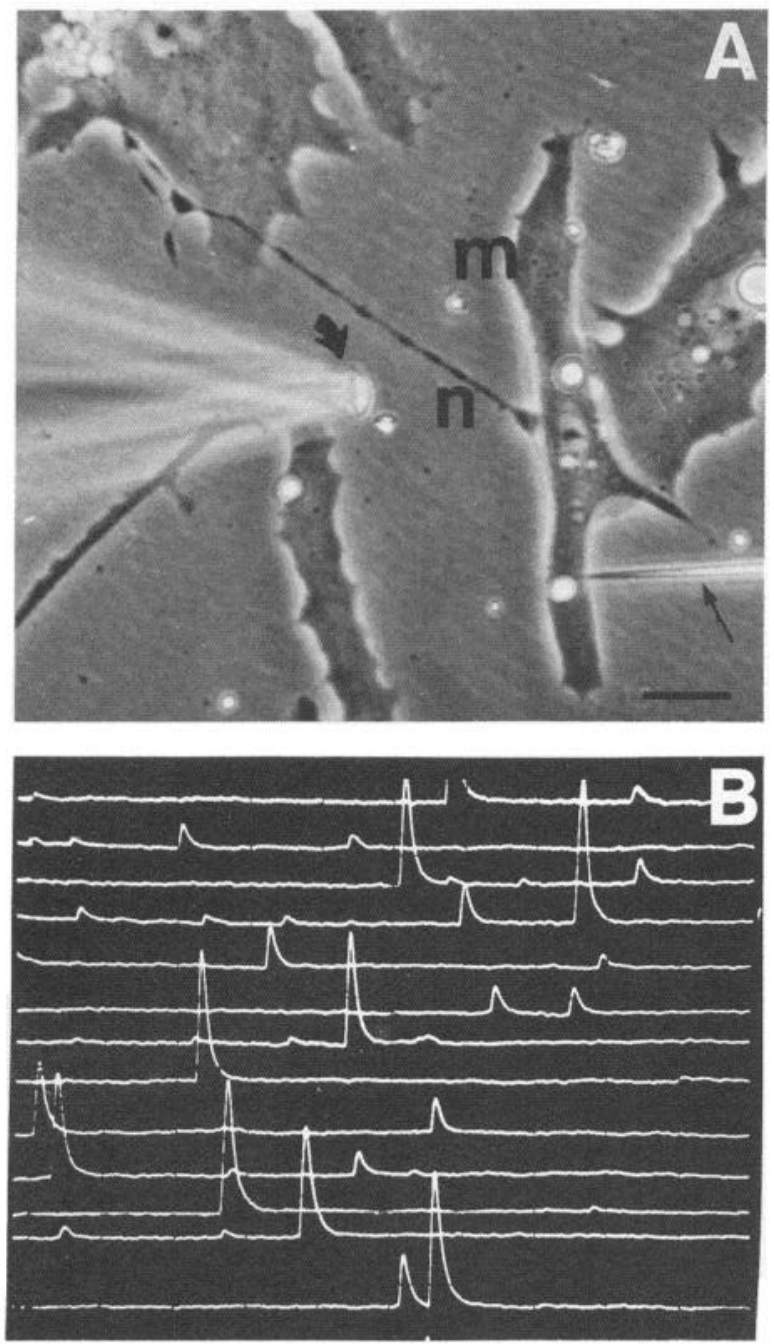

Figure 1. Synaptic connection in a Xenopus embryonic nerve-muscle culture. A, Photomicrograph of a 2-day-old culture showing a neurite $(n)$ contacting an isolated muscle cell $(m)$. The thin arrow marks the intracellular electrode impaled in the muscle cell, and the thick arrow indicates the position of the curare-containing pipette during a pulse application of curare. $B$. Typical appearance of the spontaneous MEPPs recorded by the intracellular electrode in the neurite-contacted muscle cell before the curarization. Note the varying sizes of the MEPPs. Scale, $5 \mathrm{mV}$ and $20 \mathrm{msec}$. Bar $=20$ $\mu \mathrm{m}$. these cultures (Spitzer and Lamborghini, 1976). The average peak amplitude and frequency of these MEPPs were $2.2 \pm 0.3 \mathrm{mV}$ and $1.3 \pm 0.5$ ( $n=7$ cells; \pm SEM), values close to those previously reported in similar Xenopus culture systems (Kidokoro et al., 1980). These MEPPs are much larger than that of the mature neuromuscular junction, presumbly due to the fact that these muscle cells have relatively high input resistance (50 to 100 megohms; Chow and Poo, 1984; see also Anderson et al., 1979).

In the present study, we defined a muscle cell to be "innervated" if MEPPs were detected in the cell. Failure to detect MEPPs indicates either that the neurite comes from a noncholinergic neuron or that the contact had not established communication. Previous studies have shown that in this Xenopus culture system, approximately $60 \%$ of the neurons are cholinergic ( $Y$. Kidokoro, personal communication). Analysis of the amplitude histogram of MEPPs showed well defined multiple peaks which are spaced at regular intervals ( $Y$. Sun and M. Poo, unpublished observation), indicating that the normal MEPPs in this culture were composed of discrete "subunits," and that the large MEPPs frequently observed in this culture are composed of smaller quantal units of MEPPs (cf. Kriebel and Gross, 1974).

Hyperpolarization induced by local curarization. When a pulse of saline containing $15 \mathrm{~mm}$ curare was pressure-ejected through a micropipette placed near the innervation site on a muscle cell, there was a rapid disappearance of MEPPs together with a transient hyperpolarization of the muscle membrane. Figure 2, $A$ to $C$, depicts three examples of intracellular recordings from three different muscle cells from a 1-day-old culture. Immediately following curarization, the MEPPs disappeared and the membrane became hyperpolarized. Within minutes after the curarization, the membrane potentials returned to their original level and some recovery of MEPPs was observed. The effects of local curarization observed in these experiments were not due to the pressure change associated with local ejection of curare. Local pressure ejection of recording medium containing a 100 times lower concentration of curare or $15 \mathrm{~mm}$ sucrose (Fig. 2, $D$ and $E$ ) did not induce any hyperpolarization. When curare was applied in many experiments by diffusion of the drug from the pipette without the application of pressure, similar hyperpolarization was observed. Finally, prolonged application of the curare caused prolonged hyperpolarization of the muscle membrane (see Fig. 4A) without any recovery of the MEPP activity. Assuming that the main action of curare is to block the ACh activation of muscle membrane receptors, these observations are consistent with the notion that there exists a low level, steady release of ACh from the neurite which maintains the membrane potential at a depolarized level, and the depolarization is removed by the curare block. The average hyperpolarization induced by pulse application of $15 \mathrm{~mm}$ curare in normal recording medium was $4.3 \pm 1.3 \mathrm{mV}(n$ $=13 ; \pm S D)$, and that by prolonged curarization was $6.8 \pm 2.7 \mathrm{mV}$ $(n=10 ; \pm \mathrm{SD})$.

The size of the curare-induced hyperpolarization was variable from cell to cell, but no apparent correlation with the frequency of MEPPs was found. Figure 3 plots the peak amplitude of hyperpolarization versus the frequency of MEPPs in 17 different recordings, under a variety of conditions (see "Effects of extracellular $\mathrm{Ca}^{2+}$ concentration"). This result suggests that the non-quantal component of $\mathrm{ACh}$ induced depolarization was not due to the local accumulation of ACh molecules resulting from MEPP activity. Furthermore, the amount of $\mathrm{ACh}$ required to maintain a steady depolarization of the muscle membrane of a few millivolts far exceeds that which can be supplied by the quantal release of ACh.

The above interpretation of curare's effect is complicated by the fact that in many cases the return of membrane potential following the pulsed curare application preceded that of the MEPPs. Since the recovery of both depends on the diffusion of curare from the ejected site, it appears that the concentration of curare needed to block the action of the steady "non-quantal" component of $\mathrm{ACh}$ is higher than that for the quantal component underlying MEPPs. This 
A
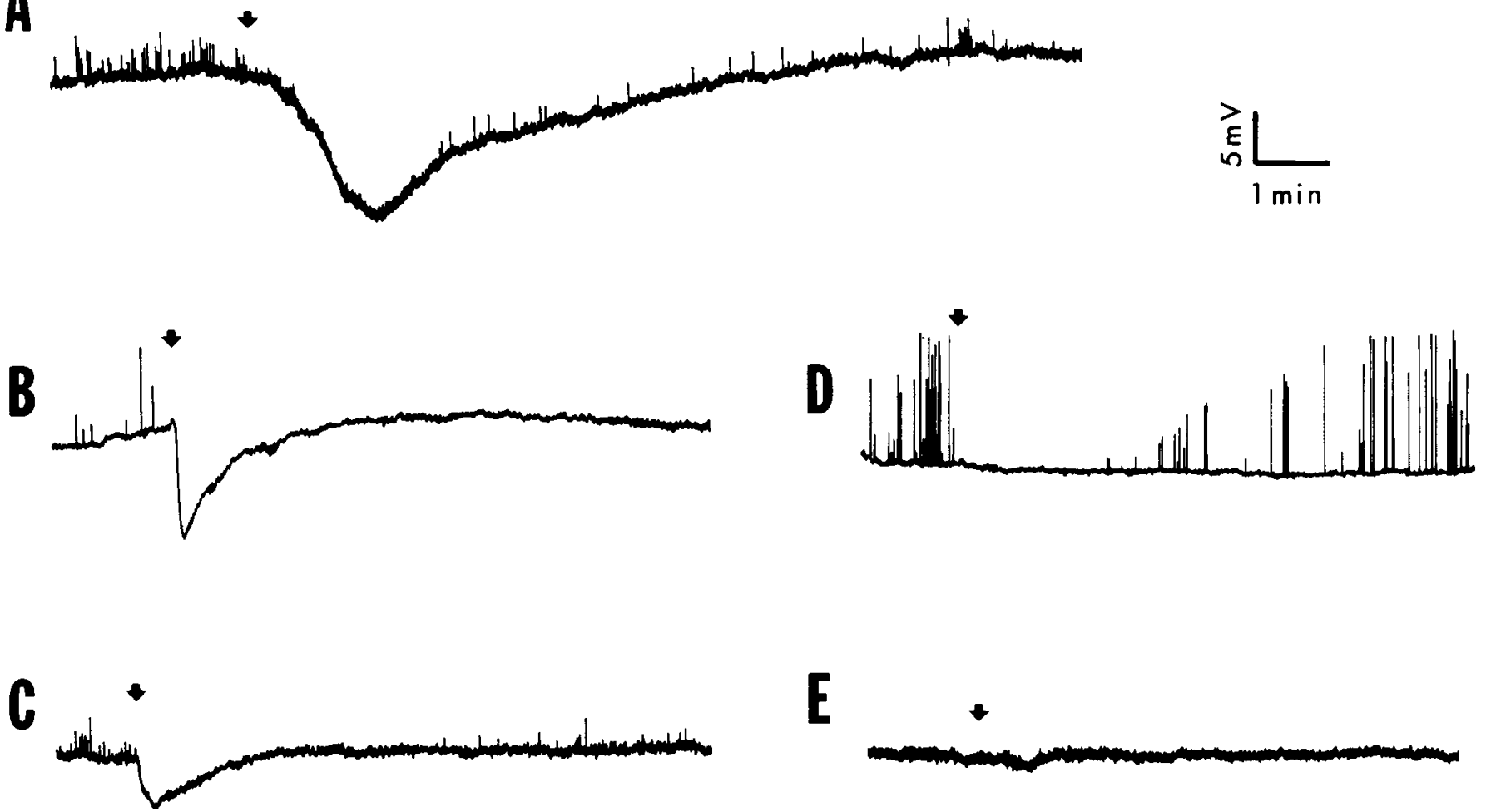

Figure 2. Hyperpolarization of muscle membrane potential induced by local application of $d$-tubocurarine. $A$ to $C$, Recordings from three different innervated muscle cells in 2-day-old Xenopus cultures. Spontaneous MEPPs (spikes) were observed before a pulse of solution containing 15 mm tubocurarine was ejected locally onto the surface of muscle cell near the site of innervation. The arrows indicate the time of curare application. Curare quickly abolished the MEPPs, and the membrane hyperpolarized with respect to the resting state. Recovery of resting membrane potential and MEPPS was seen frequently within several minutes after curarization. Notice that, in $B$, no recovery of MEPPs was observed and in $C$. membrane potential recovered before resumption of MEPPs (see the text for discussion). D. Same treatment as in A except that the concentration of curare was reduced 100 -fold to 0.15 mM. MEPPs were abolished by the curare, but no hyperpolarization was observed. $E$, Same treatment as in $A$ on a noninnervated muscle cell except that the curare was substituted with sucrose. Absence of any effect in $D$ and $E$ indicates that the hyperpolarization response of membrane potential was not due to the pressure or fluid flow associated with the local ejection of curare.

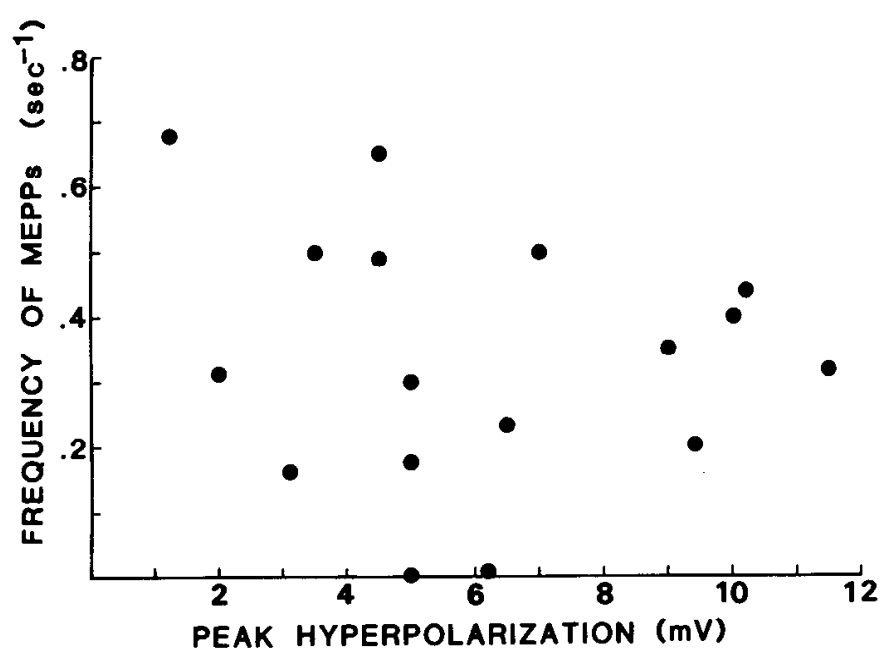

Figure 3. Curare-induced hyperpolarization versus the frequency of MEPPs. Data points represent peak amplitude of hyperpolarization recorded from innervated muscle cells with different frequency of MEPPs. Resting muscle membrane potentials were within the range of -70 to $-90 \mathrm{mV}$. No apparent relationship was observed between the frequency of MEPPs and the amplitude of hyperpolarizations induced by identical pulse applications of curare (15 mM). Data include recordings made in varying amounts of extracellular $\mathrm{Ca}^{2+}$ (see Fig. 7) possibility was also suggested by the experiments using curare at different concentrations. At $0.15 \mathrm{~mm}$ curare, pulse curarization was found to abolish completely the MEPPs without inducing a significant hyperpolarization $(0.9 \pm 0.8 \mathrm{mV}, \pm \mathrm{SD} ; N=8$; see Fig. $2 D)$. The origin of this differential effect of curare remains to be elucidated (see "Discussion").

Membrane potential of innervated versus uninnervated cells. The curare-induced response suggests that the membrane of an innervated muscle cell is kept at a depolarized state as compared to the uninnervated muscle cell due to a steady release of ACh from the neurite. This idea was tested directly by comparing the membrane potentials of the innervated versus uninnervated muscle cells without the use of curare. Despite the large variation in the recorded membrane potentials, the innervated muscle cells showed an average membrane potential of $73.7 \pm 5.1 \mathrm{mV}(n=25, \pm \mathrm{SD})$, which is indeed lower than the average potential $-79.9 \pm 4.2 \mathrm{mV}(n=30$, $\pm S D$ ) - of the uninnervated muscle cells in the same group of cultures. The difference is statistically significant ( $p<0.01, t$ test).

Effects of $\alpha$-bungarotoxin. Local application of $\alpha$-bungarotoxin ( $\alpha$-BGT, $50 \mu \mathrm{g} / \mathrm{ml}$, Sigma), a snake venom protein which blocks ACh activation of nicotinic muscle receptors in essentially irreversible fashion, also produced prolonged hyperpolarization of innervated muscle membrane (see Fig. 4B). The average amplitude of the hyperpolarization was $8.3 \pm 2.9 \mathrm{mV}(n=9, \pm \mathrm{SD})$. After blocking of ACh receptors with $\alpha$-BGT, local application of curare failed to initiate any hyperpolarization of the muscle cell (three separate experiments; see Fig. $4 C$ ), consistent with the notion that the hyperpolarization is due to the known action of curare on the ACh receptors, rather than on other curare-induced conductance changes of unknown origin. 

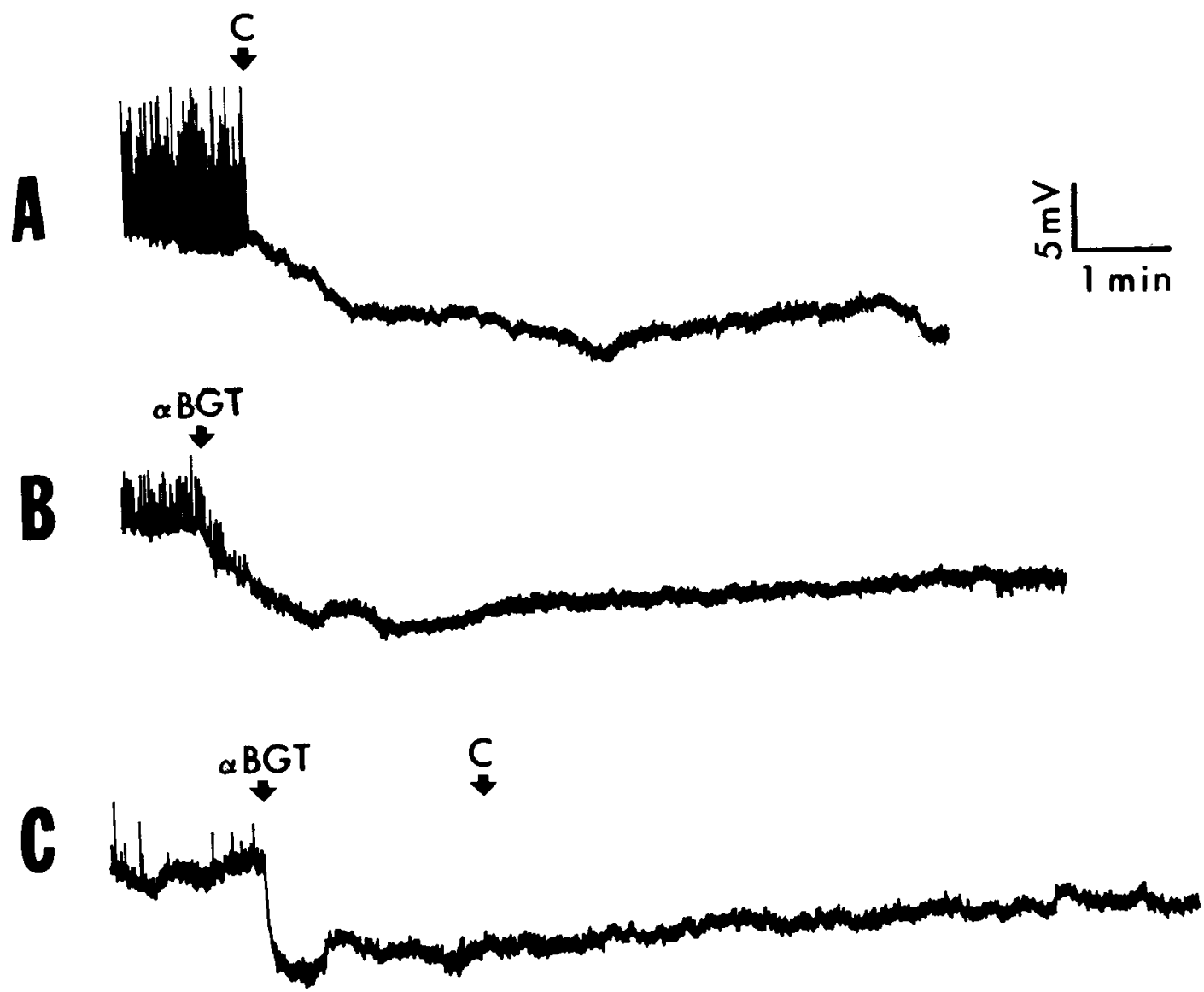

Figure 4. Effect of $\alpha$-BGT. A, Continuous ejection of curare-containing solution $(C, 15 \mathrm{~mm})$ to an innervated muscle caused prolonged hyperpolarization of the muscle membrane potential and disappearance of MEPPs. B, Local application of a pulse of solution containing $50 \mu \mathrm{g} / \mathrm{ml}$ of $\alpha$-BGT resulted in the disappearance of MEPPs and a prolonged hyperpolarization with essentially no recovery. $C$, Local application of curare (15 mM) after the muscle membrane had been treated with a pulse of $\alpha$-BGT did not induce further hyperpolarization of the membrane, suggesting that the hyperpolarization induced by curare and $\alpha$-BGT is probably due to the direct action of the drugs on the ACh receptors.

The concentration of $\alpha$-BGT ( $50 \mu \mathrm{g} / \mathrm{ml}$ ) used in this local application is rather high. Although a much lower concentration $(1 \mu \mathrm{g} / \mathrm{ml})$ is effective in abolishing MEPPs after prolonged (1 hr) incubation of the muscle cell, the latter is not used since we need to examine the membrane potential change over a reasonably short period.

The hyperpolaring effect of $\alpha$-BGT was not observed in the uninnervated muscle cell. The effect of the pulse application of $\alpha$ BGT $(50 \mu \mathrm{g} / \mathrm{ml})$ on the uninnervated muscle cells was examined by continuously recording the membrane depolarization induced by repetitive iontophoretic application of $\mathrm{ACh}$ at the cell surface, in the same manner as that shown previously (Poo, 1982; Young and Poo, 1983a). We found that pulse application of the toxin resulted in a rapid disappearance of $\mathrm{ACh}$ sensitivity without any significant alteration of the resting membrane potential of the muscle cell (see also Fig. 1 of Poo, 1982). Absence of the hyperpolarizing effect of $\alpha$ BGT in the uninnervated muscle cell suggests that the $\alpha$-BGTinduced hyperpolarization in the innervated cell was not due to some unknown toxin effect on the Xenopus embryonic muscle cells.

These iontophoretic mapping studies also showed that the $\alpha$-BGT block of the ACh receptor is essentially irreversible over the duration of the present experiment. We found that, after pulse application of $50 \mu \mathrm{g} / \mathrm{ml}$ of $\alpha$-BGT, the ACh sensitivity was completely abolished for as long as the intracellular recording of the muscle was made (up to $30 \mathrm{~min}$ ) - a result consistent with previous reports on these muscle cells (Poo, 1982; Brehm et al., 1983).

Effects of denervation. The above results suggest that the innervated muscle membrane is maintained in a depolarized state by a steady presence of ACh molecules which appear independently of the quantal ACh release associated with the MEPPs. It is possible that the culture medium contains a substantial amount of the background $A C h$ due to $A C h$ release from the neurons (Hume et al. 1983; Young and Poo, 1983b) or from other non-neuronal cells prior to the experiment. The following experiments indicate, however, that the innervating neurite is the immediate source of these non-quantal ACh molecules.

Neurites were removed mechanically from the innervated muscle cells, and the effects of denervation on the muscle membrane potential and MEPPs were examined. The muscle cell was impaled with an intracellular electrode prior to the denervation in order to monitor the immediate events following neurite removal. These experiments had a low success rate, since the process of removing the neurite frequently caused strong contraction and damage to the impaled muscle cell. A total of only eight successful cases of neurite removal were obtained in the present study. In each case, the presence of MEPPs in the innervated muscle was first confirmed by intracellular recording. The innervating neurite was then gently removed from the muscle with another micropipette by pulling the neurite at some distance away from the muscle (see Fig. 5, $A$ to $C$ ). $A$ denervation was considered successful if there was only mild contraction of the muscle during the course of neurite removal and the muscle membrane potential immediately before and after the operation was identical.

There are three main findings from these studies, as follows. (1) After neurite removal, there was a period of persistent (or an increased level of) MEPP activity. These post-denervation MEPPs, which lasted an average of $7.5 \mathrm{~min}$ (range, 2 to $12 \mathrm{~min}$ ), were presumably due to quantal $A C h$ release from the remaining remnant of nerve terminal on the muscle cell (see Fig. $5 \mathrm{C}$ ). (2) The muscle 

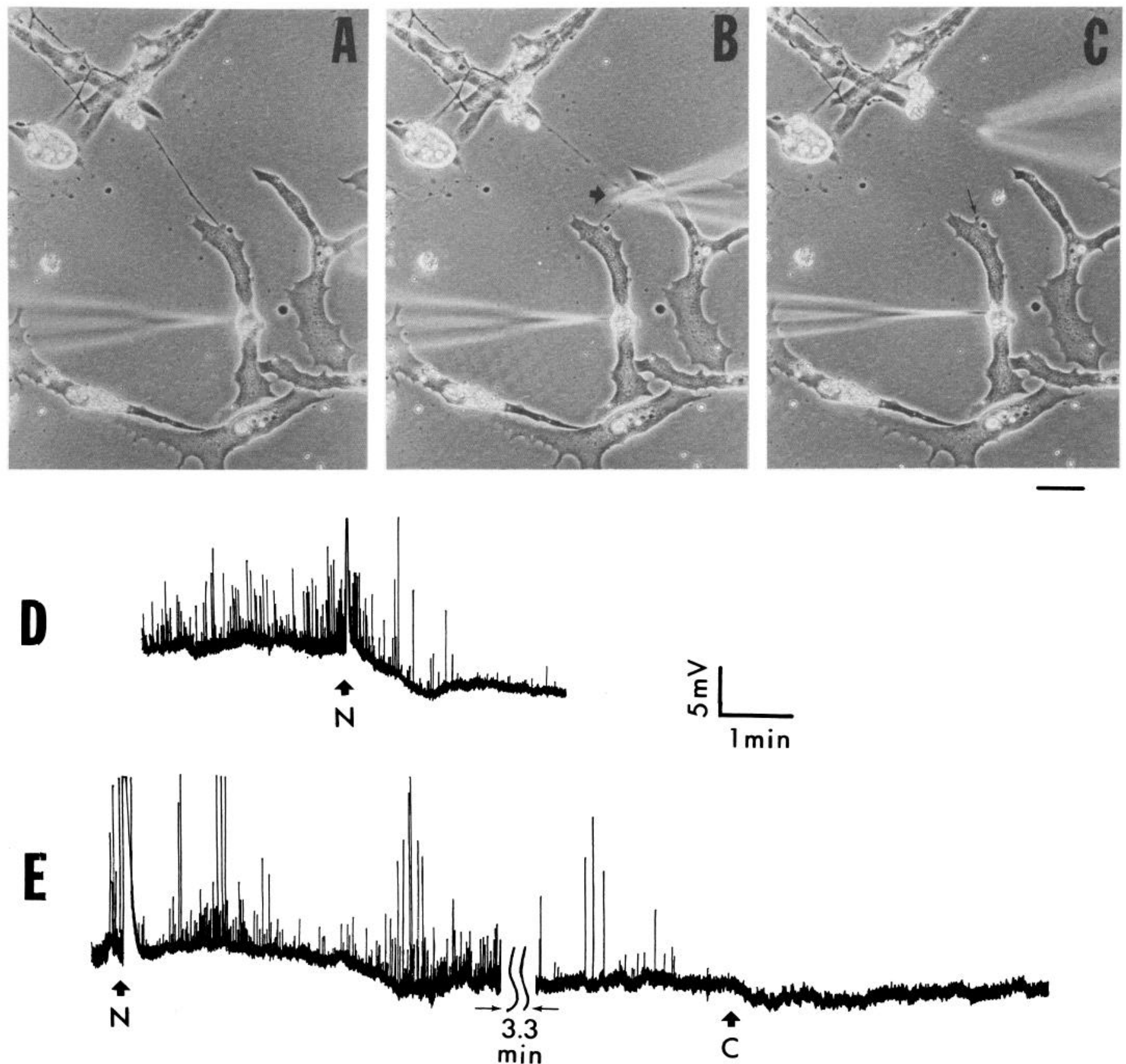

Figure 5. Effect of denervation. $A$ to $C$, Phase-contrast photographs of a nerve-muscle pair before $(A)$, during $(B)$, and after $(C)$ denervation. The muscle cell was impaled before denervation. The removal of neurite was accomplished by using a second micropipette (thick arrow). Note the absence of neurite in $C$ except for a small residual ending remaining attached to the muscle surface (thin arrow). $D$, Example of intracellular recording obtained from a muscle cell before, during, and after the denervation. Arrow $N$ marks the time of neurite detachment from the muscle. The transient depolarization immediately following the neurite detachment was due to contraction of the muscle, which subsided within a few seconds and was allowed by a return to stable membrane potential. Notice a slow hyperpolarization following the return of membrane potential and the disappearance of MEPPs. $E$, Recording from another muscle cell treated the same as that described in $D$ except that a pulse of curare $(15 \mathrm{~mm})$ was applied to the denervated muscle cell after the disappearance of the MEPPS. Note that only a small hyperpolarization was induced by the curare, and there is a relatively long period of persistent MEPP activity.

membrane potential consistently showed a hyperpolarization after denervation. The average delay between the neurite removal and the onset of hyperpolarization was $0.8 \mathrm{~min}$ (range, 0 to $2.7 \mathrm{~min}$ ), and it took an average of $3 \mathrm{~min}$ (range, 1.3 to $5 \mathrm{~min}$ ) for the hyperpolarization to plateau. The average amplitude of the denervation-induced hyperpolarization was $7.0 \pm 2.7 \mathrm{mV}(n=13 ; \pm \mathrm{SD})$, a value close to that found for prolonged application of curare and $\alpha$-BGT. This result suggests that the innervating neurite is the source of non-quantal $\mathrm{ACh}$ and its elimination deprives the muscle cell of the ACh, resulting in a hyperpolarization. (3) In all cases the postdenervation hyperpolarization occurred with a more rapid time course than that for the disappearance of the MEPPS, suggesting that non-quantal and quantal release of $\mathrm{ACh}$ operate by separate mechanisms.

Effects of curare on uninnervated and denervated muscle. When a pulse of curare $(15 \mathrm{~mm})$ was applied to the surface of an isolated Xenopus muscle cell which was not in contact with any neurite, a transient depolarization was observed in nearly all cases. Figure $6 \mathrm{~A}$ 

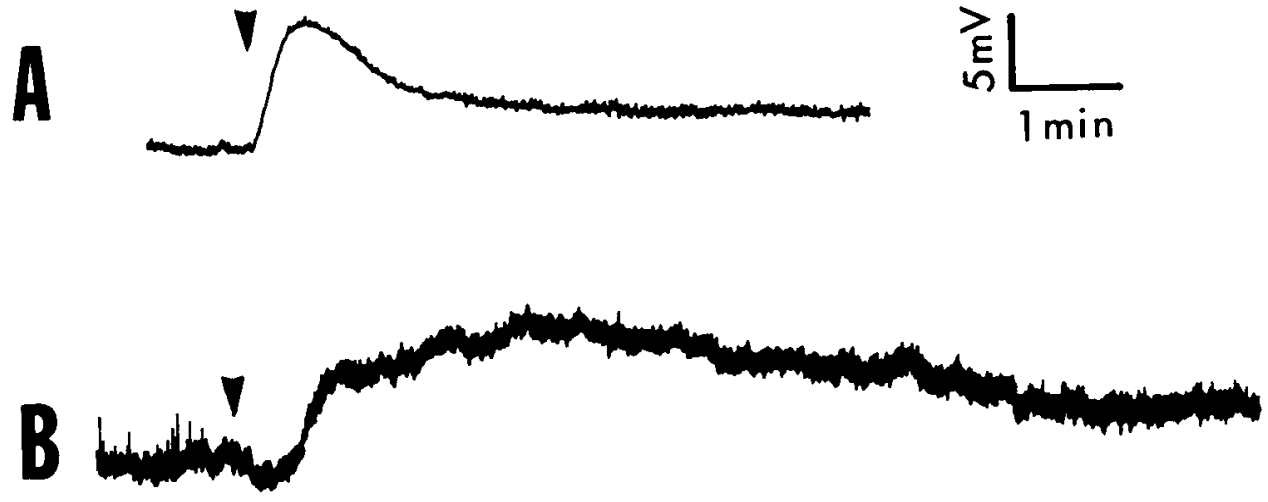

Figure 6. Comparison of curare effects on the noninnervated and innervated muscle cells. $A$, An example of membrane depolarization recorded from an isolated, noninnervated muscle cell in response to local application of a pulse of solution containing curare $(15 \mathrm{~mm})$. Application of curare was performed in the same manner as that for cells shown in Figure 2A. B, A spherical muscle cell (myoball) was pushed into con-

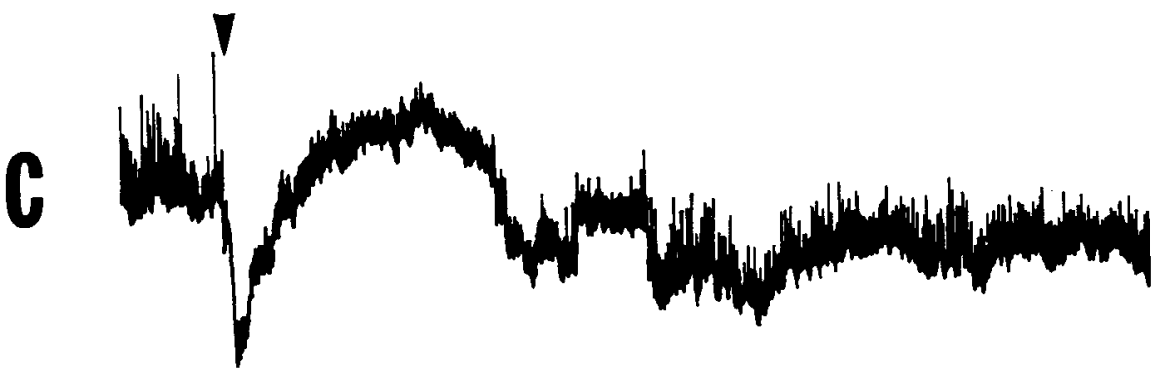
tact with the tip of a neurite, and the effect of local application of curare was examined $1 \mathrm{hr}$ after the contact. Note that the intracellular recording in the myoball before curarization showed low level MEPP activity. Curare induced a small hyperpolarization followed by a large amplitude depolarization. $C$, and $D$, Two examples of curareinduced biphasic response recorded from innervated muscle cells in 1-day-old cultures. The exact timing of innervation was uncertain. Arrows mark the time of local curare application near the synapse.

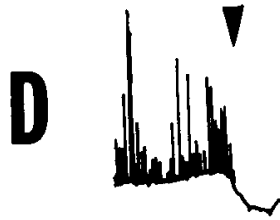

shows an example of such an experiment. The average amplitude of the depolarization was $8.0 \pm 2.5 \mathrm{mV}(n=30 ; \pm S D)$. This result shows that curare can also act as a partial agonist on embryonic Xenopus muscle cell membrane, as it can on embryonic and nconatal rat muscle (Ziskind and Dennis, 1978; Trautmann, 1982; Morris et al., 1983). As described above, the most prominent effect of curare on the innervated cell is hyperpolarization. Nevertheless, we frequently observed biphasic responses-a hyperpolarization followed by a depolarization above the resting level (Fig. $6, B$ to $D$ ). Such biphasic responses were observed in $16 \%$ of all of the recordings on innervated cells of 1- and 2-day-old cultures $(n=$ 225). Biphasic responses appeared to occur with higher frequency when the curare was applied to regions more remote from the nerve contact sites, especially in longer muscle cells (data not presented). Since the exact time that the muscle cell became innervated was unknown, we were unable to correlate the appearance of curareinduced responses with the state of maturation of a particular synapse. In one case, we used a micropipette to push a detached spherical muscle cell into contact with a growth cone. One hour later, local application of curare induced a small hyperpolarization followed by a larger depolarization of the muscle membrane potential (Fig. 6B), suggesting that, for at least $1 \mathrm{hr}$ after neurite contact, curare still produces strong agonist action.

After the neurite was removed from an innervated muscle cell and the denervation-induced hyperpolarization had reached the steady state (see "Effects of denervation"), local application of curare at the site of previous innervation yielded no significant hyperpolarizing effect comparable to that found for the innervated muscle cell. Of the eight cases tested, two showed small hyperpolarizations of 1.5 and $2 \mathrm{mV}$ (one case is shown in Fig. $5 E$ ), four cases showed depolarizations of an average amplitude of $4 \mathrm{mV}$ (range, 2 to $7 \mathrm{mV}$ ), and two cases showed no response. Although in some cases curare induced depolarization, its agonist action on the denervated muscle cell appeared to be much weaker than that on the uninnervated muscle cells in the same culture, suggesting that the contact by the neurite may have changed the response of the musclc membrane to curare.

Effects of extracellular $\mathrm{Ca}^{2+}$ concentration. Changes in the extracellular $\mathrm{Ca}^{2+}$ concentration $\left(\left[\mathrm{Ca}^{2+}\right]_{0}\right)$ are known to affect the quantal release of ACh (del Castillo and Katz, 1954). In the present study, we have examined the amplitude of curare-induced hyperpolarization of muscle membrane, as well as the amplitude and frequency of MEPPs, in the presence of different $\left[\mathrm{Ca}^{2+}\right]_{0}$. As shown in Figure 7, increasing $\left[\mathrm{Ca}^{2+}\right]_{0}$ above the normal medium concentration (1.6 $\mathrm{mm}$ ) led to a progressively decreasing amplitude of the curare-induced hyperpolarization. The hyperpolarization was completely abolished at $\left[\mathrm{Ca}^{2+}\right]_{0}$ of about $8 \mathrm{~mm}$. In sharp contrast, the frequency of spontaneous MEPPs greatly increased at higher $\left[\mathrm{Ca}^{2+}\right]_{0}$; the amplitude of MEPPs remained similar throughout all $\left[\mathrm{Ca}^{2+}\right]_{0}$ levels (data not shown). The distinctly different $\left[\mathrm{Ca}^{2+}\right]_{0}$ dependence of the two phenomena gives strong support to the notion that $\mathrm{ACh}$ release indicated by the curare effect is due to a mechanism different from that associated with quantal release of $\mathrm{ACh}$.

\section{Discussion}

The experimental strategy used in the present study was similar to that used previously for studying the non-quantal release of $\mathrm{ACh}$ at the mature neuromuscular synapses of frog sartorius muscle (Katz and Miledi, 1977) and mouse diaphragm muscle (Vyskocil and Illes, 1977). In those studies, an acetylcholinesterase (AChE) inhibitor was used to enhance the action of the released ACh. Even after the drug treatment, the hyperpolarizations produced by curarization 


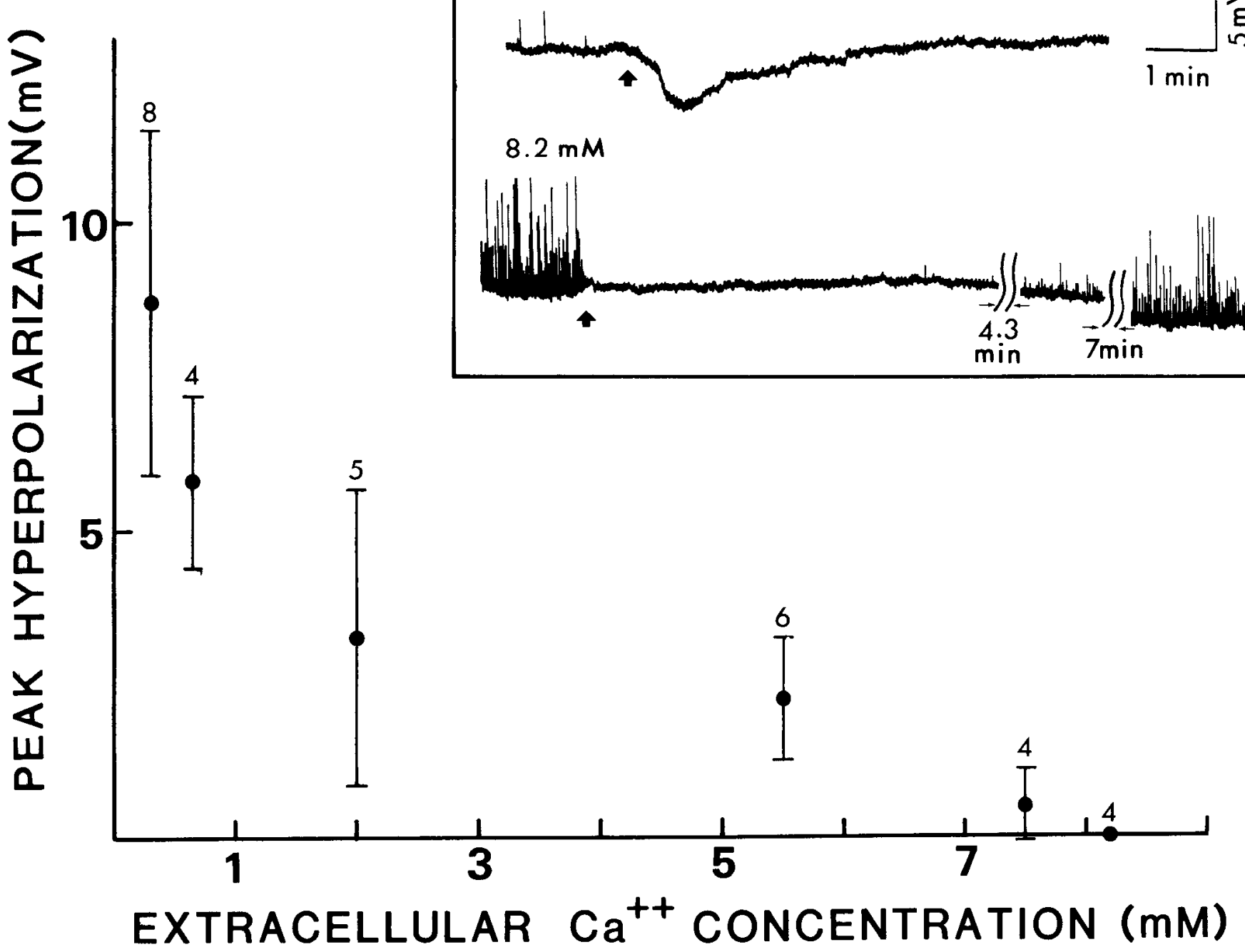

Figure 7. Effects of extracellular $\mathrm{Ca}^{2+}$ concentration $\left(\left[\mathrm{Ca}^{2+}\right]_{0}\right)$ on the curare-induced hyperpolarization and the frequency of $\mathrm{MEPPs}$. Ca ${ }^{2+}$ concentration in the culture medium varied from $0.4 \mathrm{mM}$ to $8.2 \mathrm{mM}$. The amplitude of curare-induced hyperpolarization-progressively decreased and was entirely abolished at $8.2 \mathrm{mM}\left[\mathrm{Ca}^{2+}\right]_{0}$, whereas the frequency of MEPPs was elevated with increasing $\left[\mathrm{Ca}^{2+}\right]_{0}$. Each data point represents the average amplitude of hyperpolarization recorded from different cells exposed to the same external $\mathrm{Ca}^{2+}$ concentration. The number associated with each data point indicates the number of cells recorded, and the error bars represent standard errors. Inset, Example of recordings obtained in medium containing 0.65 and $8.2 \mathrm{~mm}$ $\left[\mathrm{Ca}^{2+}\right]_{\text {. }}$. Arrows mark the time of local curare application near the synapse. Notice the complete absence of hyperpolarization and the markedly elevated frequency of MEPPs at $8.2 \mathrm{~mm}\left[\mathrm{Ca}^{2+}\right]_{\text {. }}$.

were, in general, small-in the range of $40 \mu \mathrm{V}$ to $1.5 \mathrm{mV}$. The cultured Xenopus embryonic muscle cells used in the present study have a high input resistance (Anderson et al., 1979; Chow and Poo, 1984), and their surface AChE has not yet achieved a high activity (Weldon et al., 1981). Both of these factors may account for the high amplitude of curare-induced hyperpolarization. Treatment with $\alpha$-BGT showed that the maximal level of hyperpolarization inducible by blockage of ACh reccptors was about $8 \mathrm{mV}$. This implies that in a normally innervated muscle cell, due to a steady release of ACh, the muscle membrane was kept depolarized by about $8 \mathrm{mV}$. This was confirmed further by a direct comparison of the membrane potential of innervated versus uninnervated muscle cells without the use of curare: the latter indecd had a significantly $(6 \mathrm{mV})$ higher average membrane potential. The ACh molecules responsible for the depolarization were released from the contacting neurite, since removal of the neurite from the muscle surface also induced hyperpolartization of a magnitude similar to that produced by prolonged curare and $\alpha$ BGT treatment.

Can we attribute the curare-induced hyperpolarization of the muscle membrane solely to curare's blockage of the muscle ACh receptor? Curare application did abolish reversibly the MEPPS in these cells, consistent with the well known antagonist property of curare. However, it is possible that curare may produce additional effects on other ionic channels, e.g., a selective opening of potassium channels, that could also lead to a hyperpolarization of the muscle membrane. The similarity in the hyperpolarization responses of the muscle cells to curare and $\alpha$-BGT treatments and the lack of effect of curare in muscle cells that were pre-exposed to $\alpha$-BGT suggest that both curare and $\alpha$-BGT are most likely to affect the same ionic channel-that activated by $\mathrm{ACh}$ - to produce the hyperpolarization.

The above simple scheme of curare action, however, cannot explain the finding that the concentration of curare required to induce significant hyperpolarization was one to two orders of magnitude higher than that needed to abolish MEPPs. This differential effect of curare could be due to a different sensitivity of junctional versus extrajunctional $A C h$ receptors to curare and a different distribution of the release sites or different range of action for the quantal versus 
non-quantal ACh. Previous studies (Beranek and Vyskocil, 1967 Lapa et al., 1975) have shown that the concentration of curare required to block the $\mathrm{ACh}$ sensitivity of chronically denervated muscles was one order of magnitude higher than that needed to block the endplate potentials of innervated muscles. The possibility that this differential sensitivity of $\mathrm{ACh}$ receptors to curare block presumably reflects a difference in the molecular properties between the junctional and extrajunctional receptors. This was further supported by the finding that the dissociation constant of curare binding is about 10-fold higher for the extrajunctional receptors as compared to the junctional receptors (Brockes and Hall, 1975). Our finding is thus consistent with the notion that most of the ACh molecules released through the non-quantal mode act on the extrajunctional receptors, which exist in relatively high concentration during the first few days of synaptogenesis in our Xenopus culture. A preferential action of the non-quantal $A C h$ on the extrajunctional $A C h$ receptors could result from a more diffuse or more remotely located (with respect to the muscle surface) distribution of the non-quantal release sites than the quantal release sites.

The contrasting effects of curare on the uninnervated and innervated muscle cells were striking. Uninnervated muscle cells showed depolarization upon curarization, consistent with previous findings of the partial agonist property of curare in embryonic and neonatal rat muscle cells (Ziskind and Dennis, 1978; Trautmann, 1982; Morris et al., 1983). Does curare still act as a partial agonist after the muscle has been innervated? Our results suggest that it does, at least during the initial period of innervalion. Biphasic responses (Fig. 6, $B$ to $D$ ) were observed in many innervated cells, and some denervated cells showed small but clear depolarizations upon curarization. In contrast, there is also an indication of a transition in muscle membrane properties induced by innervation: only half of the denervated muscle cells responded to curare with depolarization, and the average amplitude was smaller than that of the uninnervated cells in the same culture. Since curare acts only as an antagonist in mature muscle fibers, a transition is obligatory during the maturation of the synapse and/or muscle. The present culture system could be a useful system for future study of the time course and the nature of the transition of curare action, provided that one can control the timing of the neurite-muscle contact. In this Xenopus culture, neurites induce extensive clustering of ACh receptors at the site of muscle contact, as shown with fluorescently labeled $\alpha$-BGT (Anderson et al., 1977). In 1 to 2 day cultures used in the present study, we found that $37 \%$ of the neurite-muscle contacts (total counts 167,3 cultures) showed visible clustering of the ACh receptors after staining with fluorescent $\alpha$-BGT. Whether the clustering of the ACh receptors alters their interaction with the curare remains to be examined.

The non-quantal $\mathrm{ACh}$ release implicated by the curare-induced hyperpolarization appears to depend upon a presynaptic mechanism different from that governing the quantal $A C h$ release associated with the MEPPs. Three findings from the present study support this idea. (1) The amplitude of curare-induced hyperpolarization was independent of the frequency of the MEPPs (Fig. 3). (2) Denervationinduced hyperpolarization of the muscle membrane preceded the disappearance of MEPPs. (3) Extracellular $\mathrm{Ca}^{2+}(8 \mathrm{~mm})$ abolished the curare-induced hyperpolarization, whereas it enhanced the MEPP activity.

The sensitivity of curare-induced hyperpolarization to extracellular $\mathrm{Ca}^{2+}$ concentration is worth noting. This $\mathrm{Ca}^{2+}$ effect may be due to a presynaptic action, e.g., an inhibition of non-quantal release. Alternatively, it could result from a change in the muscle membrane properties, e.g., the affinity of ACh or curare to the ACh receptors. These problems remain to be investigated.

Some of our findings showed remarkable similarity to those obtained for mature preparations. Using histological methods, Stanley and Drachman (1981) observed that in the mature mouse diaphragm non-quantal ACh release ceases far sooner than quantal $A C h$ release. Vyskocil et al. (1983) showed that the non-quantal release of $A C h$ in the mouse diaphragm muscle was inhibited by 15
$\mathrm{mM}$ extracellular $\mathrm{Ca}^{2+}$. It thus appears that the process of nonquantal $\mathrm{ACh}$ release at the developing synapse in culture operates with a mechanism similar to that in the mature animal. The culture system provides, in contrast, more defined conditions for experimental manipulation and may prove to be advantageous in studying the cellular mechanism(s) responsible for the non-quantal release.

it has been suggested that the ACh molecule released by the non-quantal mode may act as a trophic factor at the neuromuscular junction (Katz and Miledi, 1977; Pestronk et al., 1980; Bray et al., 1982). Previous estimates of the amount of ACh released via the non-quantal mode indicate that it exceeds the amount of quantal ACh release associated with the normal MEPP activity by about two orders of magnitude (Mitchell and Silver, 1963; Fletcher and Forrester, 1975; Vizi and Vyskocil, 1979). A rough estimate of the relative amount of the ACh molecules associated with these two modes of $A C h$ release can be made by examining their relative depolarizing actions on the muscle cell. Taking the average frequency and amplitude of MEPPs recorded in our cultures, namely, $1.3 \mathrm{sec}^{-1}$ and $2.2 \mathrm{mV}$, and assuming that the amount of transient depolarization associated with each MEPP is equivalent to that of a square pulse depolarization of the same amplitude and of $10 \mathrm{msec}$ duration, we found that the total amount of "integrated" depolarization due to the MEPPs represents only $0.7 \%$ of the steady depolarization-4.3 $\mathrm{mV}$-induced by the non-quantal ACh release. This simple calculation ignores the non-linearity in the ACh action on membrane depolarization and the desensitization of the ACh receptors, both of which will lead to an underestimate of the amount of non-quantal ACh required to induce a steady depolarization. We thus conclude that the total amount of ACh released through the non-quantal mode is at least two oders of magnitude smaller than that of the quantal release underlying MEPPs.

In summary, we have shown that the phenomenon of non-quantal release can be studied at a developing neuromuscular synapse in Xenopus culture, without anti-cholinesterase treatment. Many features of the non-quantal release in this culture system resemble those found previously in mature muscle preparations. The simplicity of the culture system may prove to be advantageous for dissecting the cellular mechanism underlying this particular mode of transmitter release. Study of the nature and the effect of non-quantal ACh in a developing synapse may also help to elucidate trophic interactions between a neuron and its target cell during the early phase of synaptogenesis.

\section{References}

Anderson, M. J., M. W. Cohen, and E. Zorychta (1977) Effects of innervation on the distribution of acetylcholine receptors on cultured muscle cells. J. Physiol. (Lond.) 268: 731-756.

Anderson, M. J., Y. Kidokoro, and R. Gruener (1979) Correlation between acetylcholine receptor localization and spontaneous synaptic potentials in cultures of nerve and muscle. Brain Res. 166: 185-190.

Beranek R., and F. Vyskocil (1967) The action of tubocurarine and atropine on the normal and denervated rat diaphragm. J. Physiol. (Lond.) 188: 5366.

Bray, J. J., J. W. Forrest, and J. I. Hubbard (1982) Evidence for the role of non-quantal acetylcholine in the maintenance of the membrane potential of rat skeletal muscle. J. Physiol. (Lond.) 326: 285-296.

Brehm, P., E. Yeh, J. Patrick, and Y. Kidokoro (1983) Metabolism of acetylcholine receptors on embryonic amphibian muscle. J. Neurosci. 3: 101107.

Brockes J. P., and Z. W. Hall (1975) Acetylcholine receptors in normal and denervated rat diaphragm muscle. Il. Comparison of junctional and extrajunctional receptors. Biochemistry 14: 2100-2106.

Chow, I., and M-m. Poo (1984) Formation of electrical coupling between embryonic Xenopus muscle cells in culture. J. Physiol. (Lond.) 346: 181194

del Castillo, J., and B. Katz (1954) Quantal components of the end-plate potential. J. Physiol. (Lond.) 124: 560-573.

Fatt, P., and B. Katz (1952) Spontaneous subthreshold activity at motor nerve endings. J. Physiol. (Lond.) 117: 109-128.

Fletcher, P., and T. Forrester (1975) The effect of curare on the release of 
acetylcholine from mammalian nerve terminals and an estimate of quantum content. J. Physiol. (Lond.) 251: 131-144.

Hume, R. I., L. W. Role, and G. D. Fischbach (1983) Acetylcholine release from growth cones detected with patches of acetylcholine receptor-rich membranes. Nature 305: 632-634.

Katz, B., and R. Miledi (1977) Transmitter leakage from motor nerve endings Proc. R. Soc. Lond. (Biol.) 196: 59-72.

Kidokoro, $Y$., and $E$. Yeh (1982) Initial synaptic transmission at the growth cone in Xenopus nerve-muscle cultures. Proc. Natl. Acad. Sci. U. S. A. 79: $6727-6731$

Kidokoro, Y., M. J. Anderson, and R. Gruener (1980) Changes in synaptic potential properties during acetylcholine receptor accumulation and neurospecific interactions in Xenopus nerve-muscle culture. Dev. Biol. 78: 464-483.

Kriebel, M. E., and C. E. Gross (1974) Multimodal distribution of frog miniature endplate potentials in adult, denervated and tadpole leg muscle. J. Gen. Physiol. 64: 85-103.

Lapa, A. J., E. X. Albuquerque, and J. Daly (1975) An electrophysiologica study of the effects of $d$-tubocurarine, atropine, and $\alpha$-bungarotoxin on the cholinergic receptor in innervated and chronically denervated mammalian skeletal muscles. Exp. Neurol. 43: 375-398.

Mitchell, J. F., and A. Silver (1963) The spontaneous release of acetylcholine from the denervated hemidiaphragm of the rat. J. Physiol. (Lond.) 165 : $117-129$.

Morris, C. E., B. S. Wong, M. B. Jackson, and H. Lecar (1983) Single-channel currents activated by curare in cultured embryonic rat muscle. J. Neurosci. 3: 2525-2531.

Nieuwkoop, P. D., and J. Faber (1967) Normal Table of Xenopus laevis (Dauden), Ed. 2, Elsevier-North Holland Publishing Co., Amsterdam.

Pestronk, A., D. B. Drachman, E. F. Stanley, D. L. Price, and J. W. Griffin (1980) Cholinergic transmission regulates extrajunctional acetylcholine receptors. Exp. Neurol. 70: 690-696.
Poo, M-m. (1982) Rapid lateral diffusion of functional ACh receptors in the embryonic muscle cell membrane. Nature 295: 332-334.

Spitzer, N. C., and J. E. Lamborghini (1976) The development of the action potential mechanism of amphibian neurons isolated in culture. Proc. Natl. Acad. Sci. U. S. A. 73: 1641-1645.

Stanley, E. F., and D. B. Drachman (1981) Non-quantal ACh release in the mouse diaphragm: Effects of denervation and botulinum. Soc. Neurosci. Abstr. 7: 440

Sun, Y-a., and M-m. Poo (1983) Non-quantal release of acetylcholine at embryonic neuromuscular synapses in culture. Soc. Neurosci. Abstr. 9. 688.

Tauc, L. (1982) Nonvesicular release of neurotransmitter. Physiol. Rev. 62. 857-893.

Trautmann, A. (1982) Curare can open and block ionic channels associated with cholinergic receptors. Nature 298: 272-275.

Vizi, E. S., and F. Vyskocil (1979) Changes in total and quantal release of acetylcholine in the mouse diaphragm during activation and inhibition of membrane ATPase. J. Physiol. (Lond.) 286: 1-14.

Vyskocil F., and P. Illes (1977) Non-quantal release of transmitter at mouse neuromuscular junction and its dependence on the activity of $\mathrm{Na}^{+}-\mathrm{K}^{+}$ ATPase. Pflugers Arch. 370: 295-297.

Vyskocil, F., E. Nikolsky, and C. Edwards (1983) An analysis of the mechanisms underlying the non-quantal release of acctylcholine at the mouse neuromuscular junction. Neuroscience 9: 429-435.

Weldon, P. R., F. Moody-Corbett, and M. W. Cohen (1981) Ultrastructure of sites of cholinesterase activity on amphibian embryonic muscle cells cultured without nerve. Dev. Biol. 84: 341-350.

Young, S. H. and M-m. Poo (1983a) Rapid lateral diffusion of extrajunctional acetylcholine receptors in the developing muscle membrane of Xenopus tadpole. J. Neurosci. 3: 225-231.

Young, S. H., and M-m. Poo (1983b) Spontaneous release of transmitter from growth cone of embryonic neurone. Nature 305: 634-637.

Ziskind, L., and M. J. Dennis (1978) Depolarising effect of curare on embryonic rat muscles. Nature 276: 622-623. 